\title{
Determination of Object Temperature Influenced by Ambient Temperature as a Solution of Newton's Law of Cooling or Heating Rates
}

\section{Determinación de la temperatura del objeto influida por la temperatura ambiente como solución de la ley de Newton de las tasas de enfriamiento o calentamiento}

\author{
DOI: $10.46932 / \mathrm{sfjdv2n3-058}$
}

Received in: May 1st, 2021

Accepted in: Jun 30th, 2021

\author{
Sardjito \\ Master in Physics, Bandung Institute of Technology ( ITB ) \\ Politeknik Negeri Bandung, Indonesia \\ Full address: Politeknik Negeri Bandung, Ciwaruga-Gegerkalong Hilir-Bandung, Indonesia \\ E-mail: sardjito@polban.ac.id \\ Nani Yuningsih \\ S2-Physics, Bandung Institute of Technology ( ITB ) \\ Politeknik Negeri Bandung \\ Full address: Politeknik Negeri Bandung, Ciwaruga-Gegerkalong Hilir-Bandung, Indonesia \\ E-mail: nani.yuningsih@polban.ac.id
}

\begin{abstract}
Thermal physics experiments often require accurate data about the thermal condition of the observed object so that its temperature should be measured. The object temperature, which is observed directly using a measuring instrument, does not represent its actual thermal condition because there is an influence of the object temperature and the ambient temperature differences, especially if the object is not in adiabatic isolation. Newton's Law on cooling or heating rate is used to determine the actual object temperature if the ambient influence is eliminated. The method used in this research is matching analyses between mathematical solutions and empirical data. In thermal physics experiments in laboratories, particularly in the Basic Physics Laboratory, the influence of ambient temperature-known as Newton Correction-often uses a linear temperature-change approach to time. Thus, an analysis of the differential equation model of Newton's Law of cooling and heating rates is carried out. The result shows that the objects temperature function over time is in the form of an exponential function, both for a constant ambient temperature, and an ambient temperature that changes over time. The result of this analysis is also in line with the experimental data of the Mechanical Heat Equivalence experiment conducted in the Basic Physics Laboratory of Bandung State Polytechnic.
\end{abstract}

\section{INTRODUCTION}

The temperature measurements of experimental objects generally characterize thermal physics experiments. The results of these experiments that use the temperature of the observed object measured directly using thermometer usually slightly deviate from the supposed outcome. This condition occurs because the experiments are not adiabatical so that the influence of the ambient temperature, which is 
higher or lower than the object temperature during the experiment, is significant. For that reason, the correction to the temperature of measurement results using calculations on Newton's Law on the rate of cooling is carried out [1].

The determination of Newton's Correction is conducted by observing the object temperature, not only shortly after the experiment is completed, but also a few minutes after it is completed. How the temperature of the object depends on time needs to be questioned because the ambient temperature is higher or lower than the object temperature. The solution of Newton's Law on the rate of cooling is not simple, especially if the ambient temperature is not constant, but varies over time. The evidence of an existing experiment is contrary to Newton's cooling law statement, which confirms that the ratio of the difference between object temperature and ambient temperature and cooling rate of this quantity will be constant [2], [3]. Therefore, it needs further analysis of this model for various functions of the ambient temperature over time. If the temperature observation is performed in a long time, there may be a variation of ambient temperature changing over time. This situation often causes differences between predictions through Newton's Law and the actual object temperature, for example, the death time prediction of a corpse that was not witnessed at his death [4]. Also for soil respiration, temperature determination, especially ambient temperature is important. There are a number of variables on which the soil respiration depends, such as temperature, humidity and aeration. Factor that most influences soil respiration is the temporal variation in temperature [5]

The problem that arises is how the function of the temperature dependence of the object to time is due to the influence of higher and lower ambient temperature than the object temperature. During this time in the practice of physics involving thermal physics is conducted by assuming that the form of function between temperature and timing is linear, so if it is depicted in a temperature graph against the time will be a straight line [1]. This approach of the linear function is certainly not entirely precise, as it has no definite scientific basis [4], [6], [7]. Thus, this study aims to determine the optimal Newton Correction formulation as the basis for determining the temperature difference of calorimeter used to calculate the raised heat.

\section{RESEARCH METHOD}

The research method was preceded by modeling the condition of cooling or heating of objects by ambient temperature, which was different from the temperature of the objects, then analyzed mathematically to find the solution of the model. The proportionality constant $(\mathrm{k})$ is determined in advance from the initial terms and the boundary conditions (the measurement of the object's temperature). The determination of this mathematical solution was carried out for two circumstances, first for the constant 
ambient temperature, and second for the time-changing ambient temperature. This solution was evaluated for its significance to the experimental data obtained through the practice of Physics Experiments for the Mechanical Heat Equivalence module in the Physics Laboratory of Bandung State Polytechnic. Mechanical Heat Equivalence experiment as a module physics practicum is an essential part of the applied physics learning process because it carries the content of a conceptual understanding of conversion and energy conservation. The heat generated in a calorimeter is compared to the mechanical work given to it through the friction of the weighted rope hung to it. The calculated heat was the multiplication result between the heat capacity of a calorimeter with an increase in temperature. Measured temperature does not automatically indicate the physical temperature of a calorimeter, because the measured temperature is a resultant of calorimeter temperature with the influence of cooling rate by temperature lower than the temperature of the calorimeter. It is, therefore, necessary to make corrections to the calorimeter temperature by using the mathematical equation derived from Newton's Law.

\subsection{CONSTANT AMBIENT TEMPERATURE}

When the temperature of an object is different from the ambient temperature, it can be lower or higher. The temperature of the object will be influenced by the ambient temperature changes, with the rate of temperature change proportional to the temperature difference of object with ambient temperature. It is known as Newton's Law of cooling or heating rate [5]. If $\mathrm{T}$ is the object temperature, $\mathrm{L}$ is the ambient temperature, and $\mathrm{t}$ is time, then the Law can be written mathematically as:

$$
\frac{d T}{d t}=k(L-T)
$$

where $\mathrm{k}$ is a positive constant.

Because the temperature of the object $(\mathrm{T})$ changes at any time, then the value $(\mathrm{L}-\mathrm{T})$ changes at any time, so it is the function of time t. If the equation (1) is written by collecting temperature changes in one section, it is obtained:

$$
\frac{d T}{(L-T)}=k d t
$$

If equation (2) is integrated:

$$
\int \frac{d T}{(L-T)}=\int k d t
$$

will be obtained: 


$$
\begin{aligned}
& -\ln |L-T|=k t+c \\
& \ln |L-T|=-k t-c
\end{aligned}
$$

If the equation (5) is resolved, it is obtained:

$$
-|L-T|=e^{-k t-c}
$$

The existence of an absolute value equation as a consequence of logarithmic definitions makes equation (6) has two other answers, namely $(\mathrm{L}-\mathrm{T})$ positives, and $(\mathrm{L}-\mathrm{T})$ negatives. If the ambient temperature is higher than the temperature of the object so $(\mathrm{L}-\mathrm{T})>0$, then it applies

$$
T=L-A e^{-k t}
$$

where $A=e^{-c}$ )

and if the ambient temperature is lower than the temperature of the object so $(\mathrm{L}-\mathrm{T})<0$, then it applies

$$
T=L+A e^{-k t}
$$

where $A=e^{-c}$

Determining the temperature of an object at any time as a result of higher or lower with constant ambient temperatures can use equations (7) and equation (8). The equations can be used in an experimental observation that takes a relatively short time, not too long so that the ambient temperature can be considered constant. Meanwhile, the value of constant $\mathrm{k}$ can be determined in advance from the object temperature measurement at the beginning and the end conditions [1], [3], [4], [7].

\section{RESULTS AND DISCUSSION}

\subsection{APPLICATION OF EXPERIMENT IN FIXED AMBIENT TEMPERATURE CONDITIONS}

The experiment of mechanical heat equivalence aims to prove the Law of Energy Conservation when there is a conversion from mechanical work into heat [1], [7]. 
The mechanical work $(\mathrm{W})$ is transformed into heat $(\mathrm{Q})$ which changes the temperature of calorimeter cylinder $(\mathrm{T})$, with the value of the $\mathrm{Q}$ heat is:

$$
Q=C \cdot \Delta T
$$

where here $\mathrm{C}$ is the heat capacity of the calorimeter.

The calorimeter temperature difference $\Delta \mathrm{T}$ is calculated as a difference between the calorimeter's final temperature and its initial temperature. Because the ambient temperature is lower than the calorimeter temperature during the experimental process, the final temperature is not the real calorimeter temperature, but it has been affected by ambient temperature. The actual temperature difference should be more significant than the measured temperature difference. This temperature difference should be calculated using equation (8), through the process of increasing the temperature of the calorimeter when experiencing mechanical work. The constant, $\mathrm{K}$, is determined using data after the temperature of the calorimeter is decreasing due to the influence of lower ambient temperature, without any mechanical work. In the experiment, the calorimeter temperature is measured at a particular period during the cooling process by ambient temperature. This real temperature will be examined using equation (8).

When the calorimeter is subjected to no mechanical work cooling process, the temperature of each given time is observed. If the temperature of $T_{1}$ calorimeter to become temperature $T_{2}$ takes time $t$, then using equation (8), the constant $\mathrm{k}$ is obtained, as

$$
k=\frac{\ln \left[\frac{T_{1}-L}{T_{2}-L}\right]}{t}
$$

From the test samples of the Mechanical Heat Equivalence Experiment conducted in the Physics Laboratory of Bandung State Polytechnic, the data in columns 1 and 2 in table 1 were obtained, then determining the value of $\mathrm{k}$ and the average of its mean to $84.25 \times 10-5 \mathrm{~s}^{-1}$. From the results of $\mathrm{k}$ and then the temperature value of $T$ theoretically based on equation (7) is recalculated, the result is written in column 3.

$$
T_{2}=L+\left(T_{1}-L\right) e^{-k t}
$$

The comparison results of the data in column 2 (the temperature obtained experimentally) with the data in column 3 (the temperature values obtained theoretically) are quite significant. For more precise, Fig. 1. also shows this comparison. 
TABLE 1 . The temperature of objects as a function of time influenced by ambient temperature

\begin{tabular}{ccc}
\hline $\begin{array}{c}\text { Time }(\mathbf{t}) \\
\text { [sekon] }\end{array}$ & $\begin{array}{c}\text { Measured temperature }\left(\mathbf{T}_{\mathbf{u}}\right) \\
{\left[{ }^{\mathbf{0}} \mathbf{C}\right]}\end{array}$ & $\begin{array}{c}\text { Calculated temperature } \\
\left(\mathbf{T}_{\mathbf{t}}\right)\left[{ }^{\mathbf{0}} \mathbf{C}\right]\end{array}$ \\
\hline 0 & 32.10 & 32.10 \\
30 & 32.00 & 31.91 \\
60 & 31.80 & 31.72 \\
90 & 31.50 & 31.58 \\
120 & 31.30 & 31.36 \\
150 & 31.20 & 31.20 \\
180 & 31.10 & 31.03 \\
210 & 30.80 & 30.87 \\
240 & 30.70 & 30.71 \\
\hline
\end{tabular}

FIGURE 1. The temperature of an ambient temperature-influenced object as a function of time (Tu is the measured temperature, $\mathrm{Tt}$ is the theoretically calculated temperature)

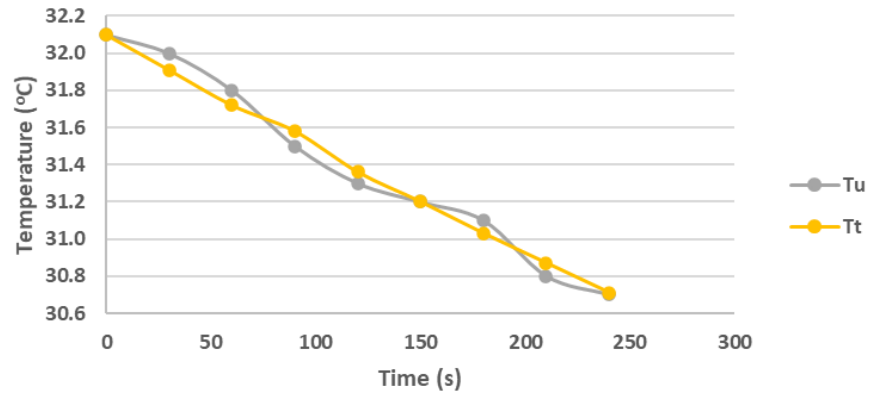

To determine the amount of heat absorbed by the calorimeter, it needs to identify the temperature difference when the calorimeter gets mechanical work. By using observation data between temperature and time when the calorimeter gets mechanical work, the temperature changes of $\Delta \mathrm{T}$ calorimeter are calculated as the difference between the final temperature $\left(\mathrm{T}_{\mathrm{A}}\right)$ and initial temperature $\left(\mathrm{T}_{\mathrm{o}}\right)$ of the calorimeter. In this case, it is not appropriate if, in the process of this increasing temperature, correction of Newton's Law is used directly to the measured $\Delta \mathrm{T}$, because this process involves the addition of mechanical energy beyond the absorbed energy due to the lower ambient temperature. Precisely, correcting the measured temperature at a particular moment with the ambient influence can obtain the corrected temperature when calculating $\Delta \mathrm{T}$ against the final temperature at the same time.

Because the ambient temperature is lower than the calorimeter temperature during the observation process, so the observed temperature, $\mathrm{T}_{\mathrm{u}}$, during the process should be corrected to become $\mathrm{T}_{\mathrm{uK}}$ using the Newton cooling equation, especially the equation (10). The illustrations are presented in Fig. 2.

FIGURE 2. An illustration of how to correct observed temperature difference 


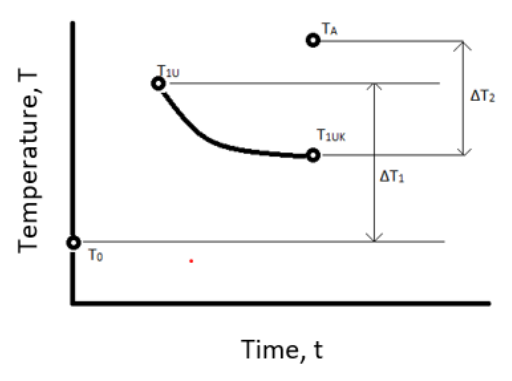

$$
\begin{array}{rlr}
\Delta T & =T_{u}-T_{0} & \text { xii) } \\
T_{u K}=T_{0}+\left(T_{u}-T_{0}\right) e^{-k t} & \text { xiii }) \\
\Delta T_{2}=T_{A}-T_{u K} & \text { xiv) } \\
\Delta T_{s}=\Delta T_{1}+\Delta T_{2} & \text { xv) }
\end{array}
$$

The calculation results of $\Delta \mathrm{T}$ and the ratio between $\mathrm{Q}$ and $\mathrm{W}$, also their comparison with direct observation without correction are presented in Table 2:

TABLE 2. Comparison between experiment results without and with correction, Mechanical Heat Equivalence

\begin{tabular}{ccccc}
\hline Observation & $\begin{array}{c}\text { Time, } \mathbf{t} \text { (before final } \\
\text { highest temperature } \\
\text { )(s) }\end{array}$ & $\Delta \mathbf{T}\left({ }^{\circ} \mathbf{C}\right)$ & $\begin{array}{c}\Delta \text { Tmean } \\
\left({ }^{\circ} \mathbf{C}\right)\end{array}$ & $\mathbf{Q} / \mathbf{W}$ \\
\hline Directly measured & 120 & 7.60 & 7.60 & 0.914 \\
& 90 & 7.73 & & \\
With correction & 60 & 7.78 & 7.75 & 0.932 \\
& 30 & 7.74 & & \\
\hline
\end{tabular}

It appears that once corrected with the cooling equation, the value of $\mathrm{Q} / \mathrm{W}$ is closer to the theoretical value (i.e., =1). Thus, it is clear that the correction of the object temperature due to the influence of the ambient temperature by using Newton's Law is more strengthening the experimental evidence of the prevailing physical theory [8], [9]

\subsection{AMBIENT TEMPERATURE CHANGES AGAINST TIME}

If the temperature observation is performed in a long time, there is a possibility of ambient temperature variation changing against time[5],[8]. Thus the ambient temperature is a function of time L $=\mathrm{L}(\mathrm{t})$. Hence, Newton's cooling rate or heating equation becomes:

$$
\frac{d T}{d t}=k[L(t)-T]
$$

Furthermore, the differential equation becomes: 


$$
\frac{d T}{d t}+k T=k L(t)
$$

The solution of this differential equation has an integral:

$$
T(t)=\{\exp (-k t)\} \int\{k \cdot \exp (k t) \cdot L(t) d t\}
$$

There are several approaches to time variation of ambient temperature. If the time is quite long, such as a full day, the ambient temperature changes fluctuated to time, for example, which Arsali examined [8], as shown in Fig. 3 (absciss is the average temperature, and the ordinate is time).

FIGURE 3. Ambient temperature variation of the local time

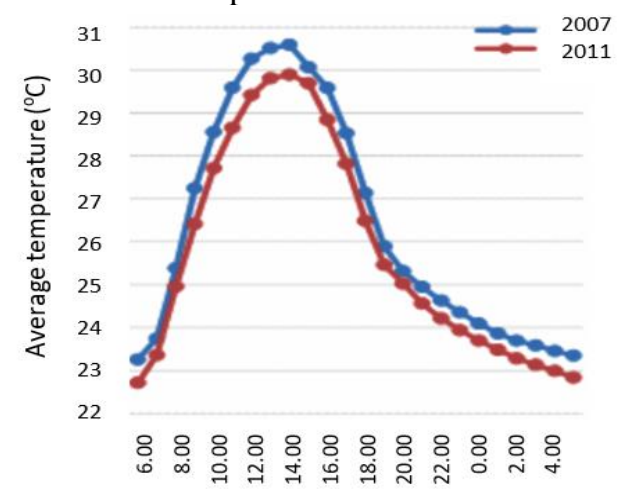

Local time

A simple approach by cutting off the end of the curve is to consider the function of the ambient temperature to time ( $\mathrm{T}$ in the clock) in the form of a sinusoid [8], [10], [11][8], [10], [11] :

$$
L=A+B \sin (C t+D)
$$

By using equation 18, the temperature of the object which is influenced by the ambient temperature is

$$
T=A+\left(\frac{k^{2}}{C^{2}+k^{2}}\right) B \sin (C t+D)-\frac{k B}{C+\frac{k^{2}}{C}} \cos (C t+D)+k E e^{-k t}
$$

Or if it is stated in ambient temperature L, 


$$
T=L-\frac{k B}{C+\frac{k^{2}}{C}} \cos (C t+D)+k E e^{-k t}
$$

By using data of experiment: $\mathrm{C}=\pi / 16$ hours- 1 and $\mathrm{D}=0$, with constant value of $\mathrm{k}=84.25 \times 10^{-}$ ${ }^{5} \mathrm{~S}^{-1}=3.033$ hour $^{-1}$, then the object temperature is affected by the sinusiodal changing ambient temperature, as

$$
T=L-(0,47 \cos 11,25 t)+\left(9,47 e^{-3,033 t}\right)
$$

With

$$
L=23+7 \sin 11,23 t
$$

Figure 4 shows variations in ambient temperature and the object temperature affected by time. The object temperature will also change according to trigonometric functions, which is a combination of sine and cosine functions to time as well as the term, which is the function of a negative exponent of time. This last term of the result from the equation (22) becomes a part that dampens the amplitude of temperature changes to time. This result, general form of equation (20), somehow has the same form as the result of other research carried out using numerical computation, consists of the constant term, sinusoid term, and damping term [2], [9].

FIGURE 4. The temperature of objects and ambient temperature as a function of the time

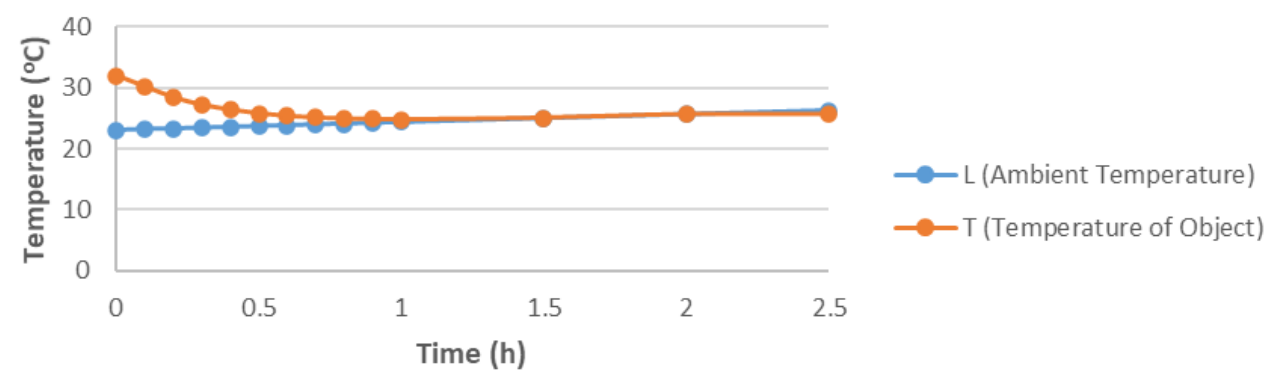

From Fig. 4, it is clear that after reaching a steady, within a sufficiently long period, if there is no addition or reduction of energy in any other form, the temperature of the object will equal or nearly equal the ambient temperature. 


\section{CONCLUSION}

If the temperature of an object is different from the ambient temperature, then over time, there will be changes in the temperature of objects that adjust to the ambience, both for a constant ambient temperature and a changing ambient temperature over time. The temperature changes of the objects are more dominated by the exponential function of the time. The correction of the object temperature occurs because equations derived from Newton's Law for cooling or heating can calculate the ambient influence, either there is another energy conversion to the object or not. Only when there is another energy conversion, the correction should be performed for measured temperatures that are already different from the ambient temperature. When the ambient temperature changes to time within a long time, then the object temperature will be almost equal or equal to the ambient temperature. So, this model and solution derived in this paper is optimal enough to determine accurate temperature difference of the object after heating which is necessary to calculate the heat generated

\section{ACKNOWLEDGMENTS}

This research has been funded by Bandung State Polytechnic through The Unit of Research and Community Service under the Individual Research scheme year 2020, with contract number B/249.86/PL1.R7/PG.00.03/2020 


\section{REFERENCES}

[1] N. Yuningsih, K. H., and S. Sardjito, "Signifikansi Koreksi Newton untuk Memasukkan Pengaruh Lingkungan pada Percobaan Tarakalor Mekanik,” 2019, doi: 10.21009/03.snf2019.02.pa.06.

[2] F. A. Godínez, M. Navarrete, O. A. Chávez, A. Merlin, and J. R. Valdés, "Two fractal versions of Newton's law of cooling," Prog. Fract. Differ. Appl., 2015, doi: 10.12785/pfda/010207.

[3] Widyastuti and Ishafit, "Penentuan Kalor Jenis Bahan menggunakan Metode Pendinginan Newton dan Sensor Suhu DS18B20 Berbasis Arduino Uno," J. Ris. dan Kaji. Pendidik. Fis., vol. 6, no. 2, pp. 16, 2019, doi: DOI: 10.12928/jrkpf.vxix.xxxx.

[4] G. Virny, "Perkiraan Lama Waktu Kematian Dengan Menggunakan Model Modifikasi Hukum Pendinginan Newton,” J. Mat. UNAND, vol. VII, no. 2, pp. 98-104, 2018.

[5] F. P. García, J. P. Méndez, B. V. Prado, and E. A. Torres, "Soil respiration and its relationship with litter contributions in a wooded mountain soil," South Florida J. Dev., vol. 2, no. 2, pp. 2382-2397, 2021.

[6] M. Gockenbach and K. Schmidtke, "Newton's law of heating and the heat equation," Involv. a J. Math., 2009, doi: 10.2140/involve.2009.2.419.

[7] N. Yuningsih, "Optimasi Besaran Fisis yang mempengaruhi Proses Konversi Energi (Studi Kasus Percobaan Tara Kalor Mekanik dan Hukum Joule)," in Prosiding Seminar Nasional Fisika (E-Journal), 2018, vol. 7, pp. SNF2018-PA.

[8] A. Arsali, O. C. Satya, S. Supardi, and I. Purna, "Penentuan Koefisien untuk Perhitungan Suhu Udara Rata-rata Harian Data Stasiun Klimatologi Palembang," J. Meteorol. dan Geofis., 2015, doi: 10.31172/jmg.v16i1.260.

[9] P. A. Maurone and C. Shiomos, "Newton's Law of Cooling with finite reservoirs," Am. J. Phys., 1983, doi: 10.1119/1.13505.

[10] J. L. Horst and M. Weber, "Joule's experiment modified by Newton's Law of Cooling," Am. J. Phys., 1984, doi: 10.1119/1.13937.

[11] C. R. Mattos and A. Gaspar, "Introducing Specific Heat Through Cooling Curves," Phys. Teach., 2002, doi: 10.1119/1.1517883. 